\title{
Role of Helicobacter Pylori Eradication in Pregnant Women with Hyperemesis Gravidarum
}

\author{
Original \\ Mostafa Abdo Ahmed ${ }^{1}$, Ayman Fathy Elsayed ${ }^{2}$,Al-Zahraa Mohammad Soliman ${ }^{3}$ \\ Article \\ ${ }^{1}$ Department of Obstetrics and Gynecology, Faculty of medicine, Lecturer of Obstetrics and \\ Gynecology, '2Department of Internal Medicine, Faculty of medicine, Lecturer of Internal \\ Medicine, ${ }^{3}$ Department of Community Medicine, Zagazig University. Assistant lecturer of \\ Community Medicine, Faculty of medicine, Zagazig University.
}

\begin{abstract}
Objective: The aim of this research is to detect the role of eradication of Helicobacter pylori in pregnant women with hyperemesis gravidarum $(\mathrm{HG})$ using modified, high dose, non-teratogenic dual therapy.

Study design: Randomized controlled trial.

Patients and methods: The study included 156 pregnant women suffering from HG with positive fecal antigen test for Helicobacter pylori. Participants were divided randomly into two groups: group A that received the traditional management for HG (diet instructions, intravenous fluids, electrolyte replacement, antiemetics and vitamins supplementation), and group $\mathrm{B}$ that received the previous management for HG plus adding eradication dual therapy for Helicobacter pylori in form of Lansoprazole $30 \mathrm{mg}$ TID + Amoxicillin $1 \mathrm{~g}$ TID for 2 weeks and the clinical response to both lines of management was evaluated in both groups two weeks after the start of management.

Results: There is a statistically significant difference between both groups as regard clinical response to the used regimen with more clinical improvement in group B.

Conclusion: There is an association between Helicobacter pylori infection and hyperemesis gravidarum, allowing us to conclude that Helicobacter pylori should be considered as one of the risk factors of HG. Screening for Helicobacter pylori should be added to the investigations of $\mathrm{HG}$, especially if prolonged or refractory to the traditional management. Modified, high dose, non-teratogenic dual therapy for eradication of Helicobacter pylori could be considered to relieve HG in intractable cases with negligible side effects.
\end{abstract}

Submitted: 24 January 2017, Accepted: 1 February 2017.

Key Words: Helicobacter, Pregnancy, Vomiting, Hyperemesis.

Corresponding Author: Mostafa Abdo Ahmed, Department of Obstetrics and Gynecology, Faculty of Medicine, Zagazig University., Tel.: (02) 01225371253, E-mail address: masallem81@gmail.com

ISSN: 2090-7265, February 2017, Vol. 7, No. 1

\section{INTRODUCTION}

Hyperemesis gravidarum $(\mathrm{HG})$ is a pregnancy induced problem, characterized by severe and persistent nausea and vomiting. HG is usually associated with ketosis and loss of weight. If not properly treated, it may cause dehydration, electrolytes disturbance, acid-base abnormalities, nutritional insufficiency, and may end in death in severe cases. Severe HG requiring hospital admission occurs in $0.3-2 \%$ of pregnant women ${ }^{1}$.

The causes of HG are still unknown, but it seems to be a multifactorial disease. Most probably, HG is the end result of different unrelated problems ${ }^{2}$. Emotional factors, genetic and gastrointestinal abnormalities, nutritional insufficiency, elevated levels of human chorionic gonadotrophin (hCG) and estrogens and immunological disturbance have been supposed to be included in HG pathogenesis. Up till now, there is no single theory which can explain $\mathrm{HG}^{2,3}$.

Helicobacter pylori (H. pylori) infection is one of the most common and endemic human infections worldwide, causing a number of very common and important gastrointestinal problems such as peptic ulcer, chronic gastritis, and gastric cancer ${ }^{4}$. Several case control studies demonstrated strong association between $\mathrm{HG}$ and $\mathrm{H}$. pylori infection ${ }^{59}$. In a systematic review, Golberg et al. found a higher prevalence of $\mathrm{HG}$ in $\mathrm{H}$. pylori-infected pregnant females than in noninfected ones ${ }^{10}$. In contrast, some studies revealed no relation between $\mathrm{HG}$ and $\mathrm{H}$. pylori ${ }^{11,12-14}$. 
H. pylori are flagellated, spiral shaped, gram negative, micro-aerophilic bacteria ${ }^{15}$. H. pylori increase gastrin secretion from the gastric antrum. There are multiple evidences which suggest that cytokines play a major role in the pathogenesis of $\mathrm{H}$. pylori-associated gastric inflammation and peptic ulcer. Moreover, infection with H. pylori leads to decreased secretion of bicarbonate, which occurs as a normal response to acidification of the duodenum and this finally results in an increased duodenal acid concentration in $\mathrm{H}$. pylori infected subjects ${ }^{16}$.

Unfortunately, up till now there is no single test that can be considered as the golden standard for the diagnosis of $\mathrm{H}$. pylori infection ${ }^{17}$. The stool antigen test is an enzymatic linked immune sorbent assay (ELISA) that detects the active and the actual presence of $\mathrm{H}$. pylori antigen in stool. Stool antigen test is the best method to determine the presence of $\mathrm{H}$. pylori after administration of eradication therapy ${ }^{18}$.

There are many choices for eradication of $\mathrm{H}$. pylori infection. The combination of a proton-pump inhibitor (PPI) and two different antibiotics for 1 to 2 weeks give the best rate of eradication in non- pregnant females ${ }^{18,19}$. When given at the proper doses, the intention-to-treat (ITT) eradication rates are in the range of $70-80 \%{ }^{20,21}$.

The success rate of standard triple therapies for $\mathrm{H}$. pylori eradication is decreasing worldwide and declined to unacceptable levels, suggesting the need for novel therapy regimens. This is because the prevalence of primary resistance towards clarithromycin and metronidazole is high. Since newer agents with elevated activity against such an infection, including resistant strains, are still lacking, optimizing the use of available antibiotics would be advantageous ${ }^{22}$. Given this development, a dual regimen using a PPI plus amoxicillin without clarithromycin administration, could provide an alternative choice if the rate of eradication is acceptable. The key benefit of this regimen is the optimal and the maximal reduction in gastric acid secretion during the period of treatment, in addition to the effective antimicrobial activity ${ }^{23}$.

Two studies revealed that eradication of $\mathrm{H}$. pylori during pregnancy could decrease the severity of $\mathrm{HG}^{24,25}$. The proper choice for $\mathrm{H}$. pylori treatment in pregnancy remains uncertain, as there is no available guideline for $\mathrm{H}$. pylori eradication in pregnant females ${ }^{18,19}$. When $H$. pylori infection is identified during pregnancy, postponement of eradication is usually recommended to be after delivery. Noteworthy, eradication treatment is considered during pregnancy only if $\mathrm{H}$. pylori infection is associated with severe nausea and vomiting ${ }^{26}$.

The aim of this research is to detect the role of eradication of Helicobacter pylori in pregnant women with hyperemesis gravidarum using modified, high dose, non-teratogenic dual therapy.

\section{PATIENTS AND METHODS}

This study was carried out in the Department of Obstetrics and Gynecology, Faculty of Medicine, Zagazig University in the period between July 2015 and December 2016 (18 months). The study included 156 pregnant women suffering from hyperemesis gravidarum. The clinical findings included persistent nausea and vomiting, weight loss $\geq 3 \mathrm{~kg}$ (compared to the $1^{\text {st }}$ documented weight measured in the first antenatal visit) and at least one positive ketonuria. They admitted to High Risk Pregnancy Unit (HRPU) in Zagazig University Hospitals for further evaluationand management.

Inclusion criteria were; (1) Gestational age ranging from 8 to 14 weeks; (2) They should previously visited the antenatal care clinic of Zagazig University Hospitals and received home management for HG (diet instructions, anti-emetics and vitamins supplementation) for at least 5 to 7 days but with no response; (3) Positive fecal antigen test (FAT), which identifies H. pylori antigen in the stool by enzyme immunoassay.

Exclusion criteria included: (1) History of peptic ulcer or $H$. pylori eradication before pregnancy, (2) History of chronic drugs administration "e.g., nonsteroidal anti-inflammatory drugs (NSAIDs)"; (3) thyroid disorders, psychiatric problems, liver or renal disorders, urinary tract infections, DM or intracranial abnormalities; (4) Suspected or known allergy to amoxicillin or lansoprazole.

The protocol of this randomized controlled trial was approved by the Institutional Research Ethical Committee of the Faculty of Medicine, Zagazig University. The patients were counseled about the benefits of the management options.

All patients and their husbands gave an informed written consent before enrollment in the study. They had the right to leave the study at any time.

Patients' full detailed histories were taken, besides, general and abdominal examination after exclusion of different medical problems. An ultrasound was done for each case to confirm a live fetus and to determine the gestational age also to exclude any obstetric causes of hyperemesis such as multiple pregnancy and gestational trophoplastic disease. We excluded patients if they administered any antibiotics, PPI or H2 blockers in the month preceding the study.

Full laboratory investigations were done to evaluate the severity of $\mathrm{HG}$ and to exclude other medical disorders (CBC- FBS-kidney and liver function tests- 
serum electrolytes- arterial blood gases-serum TSH-free T3, free T4). Urine analysis was done to detect ketone bodies and to exclude urinary tract infection.

Participants were divided randomly into two equal groups (1:1 ratio) using computer generated randomization program. Group A included 78 patients, who received the traditional management for $\mathrm{HG}$ in our HRPU (diet instructions, intravenous fluids, electrolyte replacement, anti-emetics and vitamins supplementation). Group B included 78 patients, who received the previous traditional management for HG plus eradication dual therapy for $\mathrm{H}$. pylori orally in form of Lansoprazole $30 \mathrm{mg}$ TID (FDA category B) 30 minutes before meals + amoxicillin $1 \mathrm{~g}$ TID (FDA category B) 30 minutes after meals for 2 weeks (all participants tolerated oral feeding) and the clinical response (improvement of nausea and vomiting and increased body weight) to both lines of management was evaluated in both groups two weeks after the start of management.

\section{Statistical analysis}

Data were checked and analyzed using SPSS version 20 for data processing. Data were expressed as frequency and percentage for qualitative variables and mean \pm standard deviation (SD) for quantitative one. We usedChi square test and t-test for comparison between the studied groups.

$P$ value of $<0.05$ considered significant and $P$ value of $>0.05$ is non significant.

\section{RESULTS}

In this interventional study, a total of 156 pregnant females were enrolled. They were suffering from hyperemesis gravidarum and fulfilling the inclusion as well as exclusion criteria. There was a non-significant difference between the studied groups as regard age, parity, duration of vomiting and gestational age at the time of admission as shown in Table (1). Side effects of the used regimens were generally mild and no patient stopped the drugs because of the side effects. In group A, which received the traditional management for HG only, 46 patients $(59 \%)$ showed complete clinical improvement and 32 patients $(41 \%)$ showed no improvement. On the other hand, in group B which received the eradication dual therapy in combination with the traditional management, 63 patients $(80.7 \%)$ showed complete clinical improvement and 15 patients $(19.3 \%)$ had no improvement.

A statistically significant difference ( $P$ value 0.003$)$ has been obtained between the two groups regarding response to the used regimen. More clinical improvement $(80.7 \%)$ has been observed in group B that received the traditional management for HG plus eradication therapy for H.pylori as shown in Table (2).

Cases did not respond to treatment in both groups were referred to another group of researchers for revaluation and management.

Table 1: Patients' clinical characteristics in both groups:-

\begin{tabular}{lccc}
\hline \multicolumn{1}{c}{ Variable } & $\begin{array}{c}\text { Group A } \\
\text { No. 78 } \\
\text { M } \pm \text { SD } \\
\text { Range }\end{array}$ & $\begin{array}{c}\text { Group B } \\
\text { No. 78 } \\
\text { M } \pm \text { SD } \\
\text { Range }\end{array}$ & P-value \\
\hline Age (years) & $\begin{array}{c}30.2 \pm 2.6 \\
(20-40)\end{array}$ & $\begin{array}{c}30.8 \pm 1.9 \\
(18-39)\end{array}$ & 0.1 \\
\hline $\begin{array}{l}\text { Duration of vomiting } \\
\text { (days) at the time of } \\
\text { admission }\end{array}$ & $\begin{array}{c}8.2 \pm 1.6 \\
(7-9)\end{array}$ & $\begin{array}{c}8.4 \pm 1.1 \\
(8-10)\end{array}$ & 0.36 \\
\hline $\begin{array}{l}\text { Gestational age } \\
\text { (weeks) at the time of } \\
\text { admission }\end{array}$ & $12.1 \pm 1.4$ & $11.8 \pm 1.9$ & \\
\hline $\begin{array}{l}\text { Parity } \\
\text { Nulliparous }\end{array}$ & $(9-14)$ & $(8-13)$ & 0.26 \\
Multiparous & $48(61.5 \%)$ & $50(64.1 \%)$ & \\
\hline
\end{tabular}

Table 2: Comparing the response to treatment in the study groups:-

\begin{tabular}{|c|c|c|c|}
\hline Variable & $\begin{array}{c}\text { Group A } \\
\text { No. } 78(\%)\end{array}$ & $\begin{array}{c}\text { Group B } \\
\text { No. } 78(\%)\end{array}$ & P-value ${ }^{s}$ \\
\hline $\begin{array}{l}\text { Complete } \\
\text { improvement of HG }\end{array}$ & $46(59 \%)$ & $63(80.7 \%)$ & \multirow{2}{*}{$0.003 *$} \\
\hline $\begin{array}{l}\text { No improvement } \\
\text { of HG }\end{array}$ & $32(41 \%)$ & $15(19.3 \%)$ & \\
\hline
\end{tabular}

\section{DISCUSSION}

As there is an association between $H$. pylori infection of the gastrointestinal tract and the occurrence of hyperemesis gravidarum, so this infection must be treated especially in pregnant women with intractable nausea and vomiting. Eradication therapy for $H$. pylori during fetal development may have potential risks of teratogenicity. Moreover, the alternative therapies do not appear to be convenient and are still a matter of debate. Jacoby and Porter reported successful management of persistent $\mathrm{HG}$ with positive $H$. pylori infection by administration of omeprazole, metronidazole and amoxicillin for a week ${ }^{25}$.

Being safe during pregnancy, we used amoxicillin and lansoprazole (FDA category B) for $\mathrm{H}$. pylori eradication in our patients. In context, a recent metaanalysis reported that the use of PPIs during pregnancy especially in the first-trimester is not associated with increased risk of miscarriage, congenital fetal malformations and preterm birth ${ }^{27}$. Besides, amoxicillin is a safe drug for use during pregnancy with no proven teratogenic effects. While other regimens for $\mathrm{H}$. pylori eradication "e.g., quinolones and tetracycline-based 
regimens" are contraindicated because of teratogenicity and/or non-established safety during pregnancy ${ }^{28}$.

Several studies tested the use of high dose dual regimen for $H$. pylori eradication in non-pregnant subjects revealing variable responses ${ }^{22,}{ }^{29}$. Other trials used the triple therapy for $H$. pylori eradication in pregnant females with $\mathrm{HG}^{30}$. To our knowledge, this is the first study evaluating the use of high dose nonteratogenic dual regimen for $H$. pylori eradication in pregnant women suffering from $\mathrm{HG}$.

In a Korean study, Kim SY et al. compared three times daily dual therapy (amoxicillin and lansoprazole) for two weeks with standard triple therapy (amoxicillin, clarithromycin and lansoprazole) twice daily for two weeks in non-pregnant $H$. pylori infected subjects. They concluded that dual therapy had less adverse events than triple therapy with a similar eradication rates. They preferred the dual regimen avoiding the use of clarithromycin, since Korea "their country" suffered from an increased prevalence of bacterial resistance to clarithromycin and metronidazole with corresponding decrease in $H$. pylori eradication rate ${ }^{29}$.

In another study for eradication $\mathrm{H}$. pylori in pregnant women with $\mathrm{HG}$, Abd Alwahed et al. used triple therapy (ranitidine $150 \mathrm{mg}$ twice daily, metronidazole $500 \mathrm{mg}$ twice daily and ampicillin $1000 \mathrm{mg}$ twice daily for 14 days). This regimen revealed an eradication rate of $66.6 \%$ with marked improvement of attacks of vomiting and increased body weight ${ }^{30}$. Interestingly, Strachan et al. reported a case of eradication in a 38-year-old woman using oral omeprazole $20 \mathrm{mg}$ bid, metronidazole $400 \mathrm{mg}$ bid and amoxicillin $500 \mathrm{mg}$ tid for 7 days in her $30^{\text {th }}$ week of pregnancy. This led to prompt resolution of her vomiting and improvement of her reflux symptoms ${ }^{31}$.

In the mid-1990s to early 2000s, dual therapy "amoxicillin and a proton pump inhibitor" showed eradication rates ranging from 57 to $90 \%$. These rates reached 77 to $100 \%$, when given three or four times daily ${ }^{32}$. Alike, lansoprazole $30 \mathrm{mg}$ three times daily produced significant and high acid suppression than lansoprazole $30 \mathrm{mg}$ twice daily ${ }^{33}$. In addition, amoxicillin showed time-dependent killing and its effectiveness rises with increasing doses and frequency of administration ${ }^{34}$. Based on the aforementioned, we expected that three times daily high dose dual therapy (lansoprazole and amoxicillin) would lead to more sufficient gastric acid suppression and more effective $\mathrm{H}$. pylori eradication than triple therapy with minimal or mild adverse events.

Several factors are involved in the efficacy of $\mathrm{H}$. pylori eradication. Sufficient gastric acid suppression is the cornerstone as intragastric $\mathrm{pH}$ is one of the critical determinants of success and amoxicillin is acid labile ${ }^{35}$. In 1995 Labenz et al. reported that eradication of H. pylori could be done with just a PPI and amoxicillin without the need for a second antibiotic if the $24 \mathrm{~h}$ intragastric $\mathrm{pH}$ was $>5.5^{36}$. The mechanism of action of amoxicillin in H. pylori eradication might be related to inhibition of the cell wall synthesis and this requires bacterial replication to potentiate the killing power of amoxicillin ${ }^{37}$. Moreover, $\mathrm{H}$. pylori enter a non-replicative but viable state when the $\mathrm{pH}$ of the gastric microenvironment is between 3 and $6^{38}$. In such situation, H. pylori are resistant to amoxicillin ${ }^{37}$.

A recent research by Marcus et al. revealed that ampicillin is more bactericidal at $\mathrm{pH} 7.4$ or 4.5 , but ineffective at $\mathrm{pH}$ 3.0. Furthermore, at $\mathrm{pH} 3.0$, which is the likely $\mathrm{pH}$ value at the gastric surface, gene expressions were decreased including cell envelope biosynthesis, cell division and penicillin-binding protein genes. Effective amoxicillin-based dual therapy seems to be possible and beneficial if gastric $\mathrm{pH}$ is kept nearly neutral in $24 \mathrm{~h}^{39}$.

In the current work, 46 patients (59\%) of group A, showed complete improvement after receiving the traditional management of $\mathrm{HG}$ only, which means that $\mathrm{H}$. pylori was not the actual cause of HG clinical presentation. Since, the rest of group A "i.e., 32 patients (41\%)" showed no clinical improvement after receiving the previously used regimen. This means that the cause of $\mathrm{HG}$ was persistent and need further evaluation and management, or there may other causes of HG than H. pylori.

On the other hand, in group B a total of 63 patients $(80.7 \%)$ showed complete improvement after receiving the traditional management of $\mathrm{HG}$ and modified, high dose, non-teratogenic dual therapy for eradication of $\mathrm{H}$. pylori, which, is a clue that $\mathrm{H}$. pylori infection was probably the cause of intractable HG in those patients. However, the rest of group B "i.e., 15 patients (19.3\%)", who showed no clinical response to the same regimen were infected with a highly virulent $\mathrm{H}$. pylori serotype resistant to dual therapy that needed more aggressive "triple or quadruple" therapy. Furthermore, HG actual cause may not be $\mathrm{H}$. pylori in those patients.

In conclusion; H. pylori should be considered as one of the risk factors of HG. Screening for H. pylori should be added to the investigations of $\mathrm{HG}$, especially in patients resistant or refractory to the traditional management.

Modified, high dose non-teratogenic dual therapy for eradication of $\mathrm{H}$. pylori could be considered to relieve the symptoms and signs of $\mathrm{HG}$ in intractable cases with negligible side effects.

Further research should be carried out on larger numbers of patients to validate dual therapy for eradication of $\mathrm{H}$. pylori in pregnant women with $\mathrm{HG}$. 


\section{REFERENCES}

1. Goodwin TM. Hyperemesis gravidarum. Obstet Gynecol Clin North Am. 2008; 35(3):401- 417.

2. Eliakim R, Abulafia O, Sherer DM. Hyperemesis gravidarum: A current review. Am J Perinatol. 2000;17(4):207-18.

3. Verberg MF, Gillott DJ, Al-Fardan N, Grudzinskas JG. Hyperemesis gravidarum, a literature review. Hum Reprod Update. 2005; 11(5):527 -539.

4. Everhart JE. Recent developments in the epidemiology of Helicobacter pylori. Gastroenterol Clin North Am. 2000; 29(3):559- 578.

5. Guven MA, Ertas IE, Coskun A, Ciragil P. Serologic and stool antigen assay of Helicobacter pylori infection in hyperemesis gravidarum: Which test is useful during early pregnancy? Taiwan J Obstet Gynecol. 2011; 50(1):37- 41.

6. Kazerooni T, Taallom M, Ghaderi AA. Helicobacter pylori seropositivity in patients with hyperemesis gravidarum. Int J Gynaecol Obstet. 2002; 79(3): $217-220$.

7. Salimi-Khayati A, Sharami H, Mansour-Ghanaei F, Sadri S, Fallah MS. Helicobacter pylori aeropositivity and the incidence of hyperemesis gravidarum. Med Sci Monit 2003 ;9(1): CR12-CR15.

8. Cevrioglu AS, Altindis M, Yilmazer M, Fenkci IV, Ellidokuz E, Kose S. Efficient and non-invasive method for investigating Helicobacter pylori in gravida with hyperemesis gravidarum: Helicobacter pylori stool antigen test. J Obstet Gynaecol Res. 2004; 30(2):136 -141.

9. Koçak I, Akcan Y, Ustün C, Demirel C, Cengiz L, Yanik FF. Helicobacter pylori seropositivity in patients with hyperemesis gravidarum. Int J Gynaecol Obstet. 1999; 66(3):251- 254.

10. Golberg D, Szilagyi A, Graves L. Hyperemesis gravidarum and Helicobacter pylori infection: A systematic review. Obstet Gynecol. 2007 Sep;110(3):695- 703.

11. Berker B, Soylemez F, Cengiz SD, Kose SK. Serologic assay of Helicobacter pylori infection. Is it useful in hyperemesis gravidarum? J Reprod Med 2003; 48(10): 809- 812 .

12. Jacobson GF, Autry AM, Somer-Shely TL, Pieper KL, Kirby RS. Helicobacter pylori seropositivity and hyperemesis gravidarum. J Reprod Med 2003; 48(8): 578- 582 .
13. Karadeniz RS, Ozdegirmenci O, Altay MM, Solaroglu A, Dilbaz S, Hizel N, et al. Helicobacter pylori seropositivity and stool antigen in patients with hyperemesis gravidarum. Infect Dis Obstet Gynecol 2006; 2006: 73073.

14. Aytac S, Türkay C, Kanbay M. Helicobacter pylori stool antigen assay in hyperemesis gravidarum: a risk factor for hyperemesis gravidarum or not? Dig Dis Sci 2007; 52(10): 2840- 2843.

15. 15- Soll A H. Helicobacter pylori induced gastritis. In: Bennet JC, Plum F, eds. Cecil Textbook of Medicine, 20TH edition Philadelphia: WB Saunders, 1996:659-660.

16. Olbe L, Fandriks L, Hamlet A.Conceivable mechanisms by which $\mathrm{H}$. pylori provokes duodenal ulcer disease.Clin.Gastroenterol 2000 14(1):1- 12.

17. Chey WD, Wong BCY.American College of Gastroenterology guidelineon the management of Helicobacter pylori infection.Am $J$ Gastroenter ol2007;102(8):1808-1825.

18. Cardaropoli S, Rolfo A, Todros T. Helicobacter pylori and pregnancy-related disorders. World $J$ Gastroenterol 2014 ; 20(3): 654 -664.

19. Bazzoli F, Pozzato P, Rokkas T. Helicobacter pylori: the challenge in therapy. Helicobacter 2002; 7 Suppl 1: $43-49$.

20. Vakil N, Lanza F, Schwatrz H, Barth J. Seven-day therapy for Helicobacter pylori in the United States. Aliment Pharmacol Ther 2004;20(1):99-107.

21. Cardenas VM, GrahamDY, el-Zimaity HMT, Opekun AR, Campos A, Chavez A, et al. Rabeprazole containing triple therapy to eradicate Helicobacter pylori infection on the Texas-Mexican border. Aliment Pharmacol Ther 2006; 23:295-301.

22. Zullo A, Ridola L, De Francesco V, Gatta L, Hassan C, Alvaro D, et al.High-dose esomeprazole and amoxicillin dual therapy for first-line Helicobacter pylori eradication: a proof of concept study. AnnGastroenterol2015; 28 (4): 448 -451

23. Hunt RH. PH and Hp-gastric acid secretion and Helicobacter pylori: implications for ulcer healing and eradication of the organism. Am J Gastroenterol 1993; 88(4): 481-483.

24. El Younis CM, Abulafia O, Sherer DM. Rapid marked response of severe hyperemesis gravidarum to oral erythromycin. Am J Perinatol 1998; 15(9): 533- 534. 
25. Jacoby EB, Porter KB.Helicobacter pylori infection and persistent hyperemesis gravidarum.Am J Perinatol 1999; 16(2): $85-88$

26. Crowe SE. Treatment regimens for Helicobacter pylori. UpToDate [homepage on the Internet]. 2012. c2013. Available from: http://www.uptodate.com/ contents/treatment-regimens-for-helicobacter-pylori? source $=$ see_link.

27. Gill SK, O'Brien L, Einarson TR, Koren G. The safety of proton pump inhibitors (PPIs) in pregnancy: A meta-analysis. Am J Gastroenterol 2009; 104(6): 1541- 1545.

28. Eric M, Sabo A. Teratogenicity of antibacterial agents. CollAntropol 2008; 32 (3): 919- 925.

29. Kim SY, Jung SW, Kim JH, Koo JS, Yim HJ, Park JJ, et al. Effectiveness of three times daily lansoprazole/ amoxicillindual therapy for Helicobacter pylori infection in Korea. $\mathrm{Br} \mathrm{J}$ ClinPharmacol 2011; 73(1): 140- 143.

30. Abd Alwahed AR, Elsaadany HM, Radwan AM, Noureldin MA, Kumar RK. Role Helicobacter pylori eradication in the management of hyperemesis gravidarum.Res J ObstetGynecol 2014; 7(1): 6- 13.

31. Strachan BK, Jokhi RP, Filshie GM. Persistent hyperemesis gravidarum and Helicobacter pylori.J Obstet Gynaecol 2000; 20(4): 427.

32. Furuta T, Shirai N, Takashima M, Xiao F, Hanai H, Nakagawa K, et al. Effects of genotypic differences in CYP2C19 status on cure rates for Helicobacter pylori infection by dual therapy with rabeprazole plus amoxicillin. Pharmacogenetics 2001; 11(4): 341-348.
33. Blum RA, Hunt RH, Kidd SL, Shi H, Jennings DE,Greski-RosePA. Dose-response relationship of lansoprazoleto gastric acid antisecretory effects. Aliment Pharmacol Ther 1998; 12(4): 321-327.

34. Hoffman A, Danenberg HD, Katzhendler I, Shuval R, Gilhar D, Friedman M.Pharmacodynamic and pharmacokinetic rationales for the development of an oral controlled release amoxicillin dosage form.J Control Release 1998; 54(1): 29- 37.

35. Graham DY, Fischbach L.Helicobacter pylori treatment in the era of increasing antibiotic resistance. Gut 2010;59: 1143-1153.

36. Labenz J, Stolte M, Blum AL.Intragastric acidity as a predictor of the success of Helicobacter pylori eradication: A study in peptic ulcer patients with omeprazole and amoxicillin. Gut 1995; 37(1): 39-43.

37. Graham DY, Shiotani A. New concepts of resistance in the treatment of Helicobacter pylori infections. Nat ClinPract Gastroenterol Hepatol 2008; 5(6): 321-331.

38. Scott D, Weeks D, Melchers K, Sachs G. The life and death of Helicobacter pylori.Gut 1998; 43 Suppl 1: S56-S60.

39. Marcus EA, Inatomi N, Nagami GT, Sachs G, Scott DR. The effects of varying acidity on Helicobacter pylori growth and the bactericidal efficacy of ampicillin. Aliment PharmacolTher 2012; 36(10): 972-979. 